\title{
Diversidade genética da soja entre períodos e entre programas de melhoramento no Brasil
}

\author{
Regina Helena Geribello Priolli(1), Celso Teixeira Mendes-Junior ${ }^{(1)}$, Sandra Mara Bispo Sousa ${ }^{(1)}$, \\ Neylson Eustáquio Arantes Sousa( ${ }^{(2)}$ e Eucleia Primo Betioli Contel ${ }^{(1)}$
}

\begin{abstract}
(1)Universidade de São Paulo, Fac. de Medicina de Ribeirão Preto, Dep. de Genética, Av. Bandeirantes, 3900, CEP 14049-900 Ribeirão Preto, SP. E-mail: rpriolli@rge.fmrp.usp.br, ctmendes@rge.fmrp.usp.br, maras@rge.fmrp.usp.br, epbconte@rge.fmrp.usp.br (2)Embrapa Soja, Caixa Postal 351, CEP 38001-970 Uberaba, MG. E-mail: neylson@epamiguberaba.com.br
\end{abstract}

Resumo - O objetivo deste trabalho foi detectar os efeitos do melhoramento sobre a diversidade do germoplasma da soja cultivada nas três ultimas décadas, por meio da comparação de seis programas de melhoramento e períodos de lançamento de cultivares, utilizando locos microssatélites. Em relação aos programas de melhoramento, todos os locos apresentaram diferenças significativas em suas distribuições alélicas. Alguns locos eram compostos de alelos exclusivos em alguns programas de melhoramento, enquanto outros foram compostos sempre dos mesmos alelos em maior freqüência para todos os programas. A AMOVA indicou maior porção da variância devido a cultivares dentro de programas e somente $5,3 \%(\mathrm{p}<0,05)$ devido à diferença entre programas. Quando comparados os programas de melhoramento entre si, cinco entre as 15 comparações apresentaram diferenças significativas $(\mathrm{p}<0,05)$, estando presente o programa IAC em quatro destas cinco comparações. As estimativas de variabilidade da soja entre os períodos de melhoramento avaliados indicaram que somente $1,78 \%$ da variância total foi devida à diferença entre períodos $(p>0,05)$. Os resultados sugerem que o germoplasma de soja utilizado em programas de melhoramento no Brasil manteve nível constante de diversidade genética nos últimos 30 anos, além de relativa heterogeneidade de determinados programas.

Termos para indexação: Glycine max, SSR, germoplasma, erosão genética.

\section{Soybean genetic diversity in time and among breeding programs in Brazil}

\begin{abstract}
The objective of this work was to detect the effects of plant breeding over the genetic diversity of soybean germplasm grown during the last three decades by comparing six different breeding programs and releasing intervals of soybean cultivars, using microsatellite loci. Regarding the breeding programs, all loci presented significantly different allelic distributions. Some loci presented alleles restricted to unique breeding programs, while others had a same allele being the most frequent in all the six programs. The AMOVA revealed that the major proportion of the variance occurred among cultivars within breeding programs and only 5.3\% $(\mathrm{p}<0.05)$ of the whole variance was due to differences among breeding programs. When the breeding programs were pairwise-compared, five out of the 15 comparisons showed significant differences $(\mathrm{p}<0.05)$, being the IAC program within four of them. Soybean variability estimates of the five different releasing intervals revealed that just $1.78 \%$ of the variance is due to differences among them ( $p>0.05)$. The results suggest that the soybean germplasm pool involved in breeding programs in Brazil has maintained a stable genetic diversity during the past 30 years, in addition to a relative heterogeneity of some breeding programs.
\end{abstract}

Index terms: Glycine max, SSR, germplasm, genetic erosion.

\section{Introdução}

A soja é uma planta originária da China e, deste país, expandiu-se para outras partes da Ásia, por volta do século XI a.C. Domesticada em latitudes compreendidas entre 30 e $45^{\circ} \mathrm{N}$, foi disseminada, posteriormente, para a América do Norte, Europa e América do Sul. No Brasil, desde o final do século XIX e durante muitas décadas, a soja foi plantada somente em caráter experimental por algumas instituições de pesquisa. No século XX, a partir da década de 60, entretanto, a cultura passou a adquirir importância no País, inicialmente na Região Sul (latitudes 30 a $22^{\circ} \mathrm{S}$ ), onde apresentou melhor adaptação, devido à semelhança com as regiões tradicionais de cultivo no mundo. Com a crescente demanda 
por matéria-prima protéica nos países desenvolvidos, foram observados o aumento da produção e a rápida expansão da área de cultivo desta leguminosa da Região Sul rumo ao Cerrado, latitudes 20 a $5^{\circ} \mathrm{S}$ (Urben Filho \& Souza, 1993), levando o Brasil de uma posição inexpressiva no cenário mundial para a de segundo maior produtor de soja no mundo.

Diversos programas de melhoramento genético contribuíram para o desenvolvimento de cultivares de alto rendimento e adaptadas às diferentes condições agroclimáticas do País. De acordo com Paludzyszyn Filho et al. (1993), na região tradicional de cultivo, os programas de melhoramento se basearam em introduções de linhagens desenvolvidas no Sul dos EUA, com o posterior desenvolvimento de cultivares melhor adaptadas. Na região de expansão, os programas de melhoramento genético seguiram a estratégia de desenvolvimento de linhagens adaptadas às baixas latitudes, por meio da incorporação da característica período juvenil longo (PJL).

Tais estratégias, entretanto, não foram acompanhadas de avaliações do aumento ou da redução da diversidade genética da soja cultivada. Estimativas sobre a variabilidade genética da cultura têm destacado que o germoplasma brasileiro provém de base genética restrita, tendo se originado de poucas linhagens ancestrais. Bonetti (1983) estimou que cerca de $70 \%$ das cultivares desenvolvidas para o Rio Grande do Sul, naquela data, descendiam das cultivares americanas Hill, Hood ou ambas. Hiromoto \& Vello (1986) informaram que todas as cultivares recomendadas para plantio naquele ano agrícola descendiam de 26 cultivares, sendo que deste total, apenas quatro eram responsáveis por cerca da metade daquele conjunto gênico.

Estudos revelam que os métodos e práticas modernas de melhoramento podem reduzir a diversidade genética das plantas cultivadas, aumentando a vulnerabilidade ao ataque de pragas, patógenos e estresses ambientais (Vellvé, 1993; Clunies-Ross, 1995). Análises genealógicas em soja cultivada sugeriram que o germoplasma norte-americano foi reduzido em aproximadamente um quarto de sua base genética original em 50 anos de melhoramento (Gizlice et al., 1993). Estudos com marcadores RAPD apontaram redução na diversidade genética da cultura da beterraba açucareira nos EUA devido ao melhoramento de caracteres de importância agronômica (McGrath et al., 1999). Já em estudos com o trigo cultivado, marcadores AFLP e microssatélites (SSR) não indicaram redução da diversidade genética, ao longo do tempo, na Grã-Bretanha (Donini et al., 2000) e na Argentina (Manifesto et al., 2001).
Com o objetivo de estudar os efeitos do melhoramento sobre a diversidade genética da cultura da soja no Brasil, foram estimados e comparados os níveis de diversidade e a existência de fluxo gênico de alelos microssatélites em seis programas de melhoramento e em cinco períodos de lançamento de uma amostra de cultivares do País.

\section{Material e Métodos}

\section{Material genético e extração de DNA}

Um grupo de 184 cultivares de soja, desenvolvidas por empresas públicas e instituições privadas, foi utilizado para representar as cultivares plantadas nos últimos anos no país. As sementes foram fornecidas pelo Banco Ativo de Germoplasma da Embrapa Soja, Instituto Agronômico (IAC) e Empresa de Pesquisa Agropecuária de Minas Gerais (Epamig).

Para a extração do DNA, sementes de cada cultivar foram semeadas em casa de vegetação, sendo posteriormente coletadas folhas jovens de trinta ou mais indivíduos por cultivar, congeladas em nitrogênio líquido e liofilizadas. O DNA foi isolado a partir deste conjunto de folhas pelo protocolo MINIPREP, baseado em Doyle \& Doyle (1990). A qualidade e concentração do DNA extraído foram avaliadas por eletroforese em gel de agarose $0,8 \%$ corado com brometo de etídio.

\section{Locos SSR}

Foram selecionados 12 pares de iniciadores que flanqueiam regiões de microssatélites em soja, desenvolvidos por Cregan et al. (1999). Os iniciadores denominados Satt002, Satt005, Satt009, Satt102, Satt173, Satt263, Satt307, Satt308, Satt309, Satt335, Satt406 e Sct_189, foram sintetizados pela Bio Synthesis Inc., Texas, EUA. As sequiências estão disponíveis no portal do Departamento de Agricultura dos Estados Unidos (2003). Os iniciadores estão localizados em 12 dos 20 grupos de ligação e foram escolhidos pelo polimorfismo apresentado em estudos prévios (Cregan et al., 1999) e pelo fato de as unidades de repetição dos microssatélites serem constituídas por um trinucleotídeo.

\section{Condições de amplificação dos locos SSR}

As reações de amplificação foram realizadas em cada um dos 184 genótipos, utilizando iniciadores específicos de cada loco. A reação foi realizada em um volume total de $25 \mu \mathrm{L}$ contendo 30 ng de DNA genômico de soja, $0,2 \mu \mathrm{M}$ de cada iniciador 3' e 5', $200 \mu \mathrm{M}$ de cada desoxirribonucleosídeo trifosfato (dNTP), solução tampão de PCR contendo $50 \mathrm{mM}$ de $\mathrm{KCl}, 10 \mathrm{mM}$ de Tris$\mathrm{HCl}, \mathrm{pH}$ 8,9, 2,0 $\mathrm{mM}$ de $\mathrm{MgCl}_{2}$ e uma unidade da enzima 
Taq DNA-polimerase. As concentrações de $\mathrm{MgCl}_{2}$ foram modificadas para 2,5 mM nas reações de PCR dos iniciadores Satt002, Satt005 e Satt009 a fim de se obter melhor amplificação. O ciclo total de amplificação foi realizado em um termociclador programado para iniciar com 2 minutos a $94^{\circ} \mathrm{C}$ seguidos por 32 ciclos com 1 minuto de desnaturação a $94^{\circ} \mathrm{C}, 1$ minuto de pareamento a $47^{\circ} \mathrm{C}, 1$ minuto de extensão a $72^{\circ} \mathrm{C}$ e 10 minutos a $72^{\circ} \mathrm{C}$ para extensão final.

Os produtos de amplificação foram separados sob condições desnaturantes em gel de poliacrilamida a $10 \%$, uréia $8 \mathrm{M}$ e tampão Tris $0,9 \mathrm{M}$ contendo EDTA $20 \mathrm{mM}$ e ácido bórico $0,8 \mathrm{M}$ por 4 horas a $15 \mathrm{~mA}$. Os fragmentos obtidos foram detectados com nitrato de prata segundo protocolo de Sanguineti et al. (1994). A amplitude de variação do tamanho de cada produto de PCR de cada loco foi estimada por meio de comparação com o marcador de tamanho de 25 pb e também através de imagem digital obtida pelo Programa Kodak 1D 3.5.

\section{Análises estatísticas}

As análises foram realizadas no conjunto das cultivares, organizadas segundo os programas de melhoramento e os períodos de lançamento. Nos agrupamentos dentro de programas, procurou-se manter aqueles com um número representativo de cultivares. Os agrupamentos relativos a períodos consideraram variações de cinco anos, de modo a retratar a dinâmica de expansão da cultura, além das cultivares características de cada época.

Os programas FSTAT versão 2.8 (Goudet, 1995), GENEPOP versão 3.3 (Raymond \& Rousset, 1995b), ARLEQUIN versão 2.0 (Schneider et al., 2000) e GDA
(Lewis \& Zaykin, 1997) foram utilizados para analisar cada grupo de dados. FSTAT foi utilizado para estimar o polimorfismo genético de cada loco por programa de melhoramento e por período de lançamento. GENEPOP foi usado para obter as frequiências alélicas e averiguar diferenças em suas distribuições dentro dos programas de melhoramento e dos períodos de lançamento, pelo teste exato de Raymond \& Rousset (1995a). O ARLEQUIN foi utilizado para estimar as diferenças genéticas entre programas de melhoramento e entre períodos de lançamento, pela análise de variância molecular (AMOVA) estimada para os 12 locos SSR. A análise da estatística $\mathrm{F}$, utilizando o parâmetro $F_{S T}$, que estima o fluxo gênico a partir da variância das freqüências gênicas entre subpopulações, foi feita por meio do programa GDA, o qual permitiu a diferenciação entre os pares de programa de melhoramento e entre os pares de períodos de lançamento das cultivares, sendo testada a significância pelo procedimento de bootstrap com 1.000 replicações.

\section{Resultados e Discussão}

\section{Variabilidade genética entre programas de melho- ramento}

As cultivares analisadas apresentaram 63 alelos distribuídos em 12 locos, variando de quatro (locos Satt406, Satt002, Satt335, Satt307, Satt309 e Satt102) a oito alelos (loco Satt173), dentro dos seis programas de melhoramento (Tabela 1). O índice de diversidade variou de 0,435 (Satt102) a 0,809 (Satt308), com um valor médio de 0,632 .

Tabela 1. Número de alelos e índices de diversidade genética (DG) por loco em programas de melhoramento ${ }^{(1)}$.

\begin{tabular}{|c|c|c|c|c|c|c|c|c|c|c|c|c|c|c|c|}
\hline \multirow[t]{2}{*}{ Loco } & \multicolumn{7}{|c|}{ Número de alelos } & \multicolumn{8}{|c|}{ Diversidade genética por loco e população } \\
\hline & $\begin{array}{c}\text { Embr } \\
(\mathrm{n}=70)^{(2)}\end{array}$ & $\begin{array}{l}\text { AgGo } \\
(\mathrm{n}=9)\end{array}$ & $\begin{array}{l}\text { Cood } \\
(n=11)\end{array}$ & $\begin{array}{l}\text { Indu } \\
(\mathrm{n}=8)\end{array}$ & $\begin{array}{l}\text { IAC } \\
(n=18)\end{array}$ & $\begin{array}{l}\text { Mons } \\
(n=38)\end{array}$ & $\begin{array}{c}\text { Total } \\
(n=154)\end{array}$ & & $\begin{array}{c}\text { Embr } \\
(n=70)\end{array}$ & $\begin{array}{l}\text { AgGo } \\
(n=9)\end{array}$ & $\begin{array}{c}\text { Cood } \\
(n=11)\end{array}$ & $\begin{array}{c}\text { Indu } \\
(\mathrm{n}=8)\end{array}$ & $\begin{array}{c}\text { IAC } \\
(n=18)\end{array}$ & $\begin{array}{l}\text { Mons } \\
(n=38)\end{array}$ & $\begin{array}{l}\text { Total } \\
(n=154)\end{array}$ \\
\hline Satt308 & 7 & 5 & 5 & 5 & 6 & 6 & 7 & & 0,824 & 0,792 & 0,782 & 0,857 & 0,810 & 0,791 & 0,809 \\
\hline Sct_189 & 5 & 4 & 4 & 4 & 4 & 5 & 5 & & 0,669 & 0,806 & 0,818 & 0,786 & 0,716 & 0,765 & 0,758 \\
\hline Satt406 & 4 & 4 & 4 & 3 & 3 & 4 & 4 & & 0,598 & 0,750 & 0,718 & 0,643 & 0,582 & 0,668 & 0,659 \\
\hline Satt309 & 3 & 3 & 2 & 3 & 3 & 2 & 4 & & 0,506 & 0,722 & 0,327 & 0,464 & 0,701 & 0,507 & 0,537 \\
\hline Satt 102 & 4 & 2 & 2 & 3 & 3 & 4 & 4 & & 0,338 & 0,222 & 0,509 & 0,607 & 0,585 & 0,363 & 0,435 \\
\hline Satt335 & 4 & 3 & 3 & 3 & 3 & 4 & 4 & & 0,557 & 0,486 & 0,468 & 0,679 & 0,493 & 0,713 & 0,567 \\
\hline Satt263 & 4 & 4 & 4 & 3 & 4 & 4 & 5 & & 0,682 & 0,694 & 0,764 & 0,464 & 0,755 & 0,696 & 0,678 \\
\hline Satt307 & 3 & 3 & 3 & 3 & 4 & 3 & 4 & & 0,553 & 0,556 & 0,564 & 0,714 & 0,608 & 0,364 & 0,557 \\
\hline Satt 173 & 7 & 6 & 4 & 2 & 5 & 7 & 8 & & 0,765 & 0,819 & 0,800 & 0,250 & 0,673 & 0,580 & 0,652 \\
\hline Satt009 & 7 & 4 & 6 & 3 & 4 & 7 & 7 & & 0,798 & 0,792 & 0,818 & 0,607 & 0,676 & 0,812 & 0,752 \\
\hline Satt002 & 3 & 3 & 3 & 3 & 3 & 3 & 4 & & 0,570 & 0,667 & 0,636 & 0,679 & 0,621 & 0,558 & 0,620 \\
\hline Satt005 & 5 & 2 & 3 & 2 & 5 & 4 & 7 & & 0,578 & 0,500 & 0,564 & 0,250 & 0,804 & 0,631 & 0,559 \\
\hline Média & 4,67 & 3,58 & 3,58 & 3,08 & 3,92 & 4,42 & 5,25 & DG & 0,620 & 0,651 & 0,647 & 0,583 & 0,669 & 0,621 & 0,632 \\
\hline Total & 56 & 43 & 43 & 37 & 47 & 53 & 63 & $\pm \mathrm{SD}$ & 0,04 & 0,05 & 0,05 & 0,06 & 0,03 & 0,04 & 0,03 \\
\hline
\end{tabular}

${ }^{(1)}$ Embr: Embrapa; AgGo: Agência Goiana e Emater (GO); Cood: Coodetec; Indu; Indusem e Rudiger Boye; IAC: Instituto Agronômico; Mons: Monsoy; SD: erro padrão. ${ }^{(2)}$ Tamanho amostral. 
O programa de melhoramento da Embrapa foi o que apresentou maior número médio de alelos $(4,67)$ e o da Indusem/RB, o menor $(3,08)$. Estes resultados já eram esperados, considerando o número total de indivíduos analisados em cada programa de melhoramento, $70 \mathrm{da}$ Embrapa e oito da Indusem/RB. Entretanto, em relação aos índices de diversidade genética, os maiores valores não foram para as amostras do programa com o maior número de alelos encontrados, mas para as do programa IAC, seguidas pelas amostras da Agência Goiana/Emater (GO), Coodetec, Monsoy, Embrapa e Indusem/RB.
Os alelos 159 (Satt309), 166 (Satt307), 121 (Satt002), 153 e 198 (Satt005), foram exclusivos de alguns programas de melhoramento (Tabela 2). Embora todos estes locos tenham se apresentado polimórficos nos respectivos programas, apenas os alelos 159 (Satt309), 166 (Satt307) e 198 (Satt005), revelaram freqüências superiores a 0,01 na população total, caracterizando polimorfismo, segundo Hartl (1997). Do total de alelos detectados, 37 (cerca de 59\%) não estiveram presentes em alguns programas de melhoramento. A presença de alelos exclusivos de determinados grupos já havia sido

Tabela 2. Freqüências gênicas de 12 locos SSR em seis programas de melhoramento de soja e valores de probabilidade obtidos para diferenciação gênica. Os alelos mais comuns de cada loco em cada programa de melhoramento estão entre parênteses ${ }^{(1)}$.

\begin{tabular}{|c|c|c|c|c|c|c|c|c|}
\hline \multirow[t]{2}{*}{ Loco } & \multirow{2}{*}{$\begin{array}{l}\text { Alelo } \\
(\mathrm{pb})\end{array}$} & \multicolumn{7}{|c|}{ Freqüências gênicas } \\
\hline & & $\begin{array}{l}\text { Embr } \\
(n=70)^{(2)}\end{array}$ & $\begin{array}{l}\text { AgGo } \\
(n=9)\end{array}$ & $\begin{array}{c}\text { Cood } \\
(n=11)\end{array}$ & $\begin{array}{l}\text { Indu } \\
(\mathrm{n}=8)\end{array}$ & $\begin{array}{c}\text { IAC } \\
(n=18)\end{array}$ & $\begin{array}{l}\text { Mons } \\
(n=38)\end{array}$ & $\begin{array}{c}\text { Total } \\
(n=154)\end{array}$ \\
\hline \multirow[t]{7}{*}{ Satt308* } & 147 & 0,043 & $-(3)$ & 0,182 & - & 0,278 & - & 0,065 \\
\hline & 162 & 0,186 & 0,056 & 0,182 & $(0,375)$ & 0,167 & 0,237 & 0,198 \\
\hline & 168 & 0,214 & 0,111 & 0,091 & 0,125 & $(0,333)$ & 0,263 & 0,221 \\
\hline & 171 & 0,043 & - & 0,091 & 0,125 & 0,056 & 0,039 & 0,049 \\
\hline & 174 & 0,071 & 0,222 & - & - & - & 0,132 & 0,078 \\
\hline & 186 & $(0,229)$ & $(0,444)$ & - & 0,125 & 0,056 & 0,039 & 0,153 \\
\hline & 192 & 0,214 & 0,167 & $(0,455)$ & 0,250 & 0,111 & $(0,289)$ & $(0,237)$ \\
\hline \multirow[t]{5}{*}{ Sct_189* } & 178 & $(0,514)$ & $(0,333)$ & $(0,273)$ & $(0,375)$ & 0,194 & $(0,382)$ & $(0,409)$ \\
\hline & 181 & 0,079 & - & 0,182 & $(0,375)$ & 0,111 & 0,171 & 0,123 \\
\hline & 202 & 0,050 & 0,111 & $(0,273)$ & - & 0,222 & 0,132 & 0,107 \\
\hline & 205 & 0,221 & $(0,333)$ & $(0,273)$ & 0,125 & $(0,472)$ & 0,237 & 0,260 \\
\hline & 211 & 0,136 & 0,222 & - & 0,125 & - & 0,079 & 0,101 \\
\hline \multirow[t]{4}{*}{ Satt406* } & 257 & $(0,543)$ & 0,333 & $(0,500)$ & $(0,563)$ & $(0,472)$ & $(0,447)$ & $(0,497)$ \\
\hline & 263 & 0,129 & $(0,444)$ & 0,182 & 0,125 & - & 0,171 & 0,146 \\
\hline & 350 & 0,014 & 0,111 & 0,091 & - & 0,056 & 0,039 & 0,036 \\
\hline & 353 & 0,314 & 0,111 & 0,227 & 0,313 & $(0,472)$ & 0,342 & 0,321 \\
\hline \multirow[t]{4}{*}{ Satt309* } & 138 & 0,336 & 0,333 & 0,182 & $(0,750)$ & $(0,361)$ & 0,447 & 0,377 \\
\hline & 144 & $(0,621)$ & $(0,444)$ & $(0,818)$ & 0,125 & 0,306 & $(0,553)$ & $(0,545)$ \\
\hline & 147 & 0,043 & - & - & 0,125 & 0,333 & - & 0,065 \\
\hline & 159 & - & 0,222 & - & - & - & - & 0,013 \\
\hline \multirow[t]{4}{*}{ Satt102* } & 147 & 0,050 & 0,111 & 0,364 & 0,125 & 0,306 & 0,039 & 0,107 \\
\hline & 156 & 0,107 & - & - & 0,250 & 0,111 & 0,145 & 0,110 \\
\hline & 159 & $(0,807)$ & $(0,889)$ & $(0,636)$ & $(0,625)$ & $(0,583)$ & $(0,789)$ & $(0,760)$ \\
\hline & 165 & 0,036 & - & - & - & - & 0,026 & 0,023 \\
\hline \multirow[t]{4}{*}{ Satt335* } & 150 & 0,021 & - & - & - & - & 0,053 & 0,023 \\
\hline & 156 & $(0,621)$ & $(0,722)$ & $(0,727)$ & $(0,500)$ & $(0,694)$ & $(0,355)$ & $(0,571)$ \\
\hline & 162 & 0,171 & 0,167 & 0,136 & 0,375 & 0,111 & 0,289 & 0,201 \\
\hline & 168 & 0,186 & 0,111 & 0,136 & 0,125 & 0,194 & 0,303 & 0,205 \\
\hline \multirow[t]{5}{*}{ Satt263* } & 214 & - & 0,111 & 0,091 & - & $(0,333)$ & - & 0,052 \\
\hline & 223 & 0,157 & 0,111 & - & 0,125 & 0,222 & 0,224 & 0,166 \\
\hline & 235 & 0,071 & - & 0,182 & - & - & 0,053 & 0,058 \\
\hline & 238 & $(0,400)$ & 0,222 & $(0,364)$ & 0,125 & 0,111 & 0,303 & 0,315 \\
\hline & 247 & 0,371 & $(0,556)$ & $(0,364)$ & $(0,750)$ & $(0,333)$ & $(0,421)$ & $(0,409)$ \\
\hline \multirow[t]{4}{*}{ Satt307* } & 166 & - & - & - & - & 0,111 & - & 0,013 \\
\hline & 175 & 0,086 & 0,222 & 0,091 & 0,250 & 0,167 & 0,105 & 0,117 \\
\hline & 181 & $(0,579)$ & $(0,667)$ & $(0,636)$ & $(0,500)$ & $(0,611)$ & $(0,789)$ & $(0,640)$ \\
\hline & 193 & 0,336 & 0,111 & 0,273 & 0,250 & 0,111 & 0,105 & 0,231 \\
\hline
\end{tabular}


Tabela 2. Continuação.

\begin{tabular}{|c|c|c|c|c|c|c|c|c|}
\hline \multirow[t]{2}{*}{ Loco } & \multirow{2}{*}{$\begin{array}{l}\text { Alelo } \\
(\mathrm{pb})\end{array}$} & & \multicolumn{6}{|c|}{ Frequiências gênicas } \\
\hline & & $\begin{array}{l}\text { Embr } \\
(\mathrm{n}=70)^{(2)}\end{array}$ & $\begin{array}{l}\text { AgGo } \\
(n=9)\end{array}$ & $\begin{array}{c}\text { Cood } \\
(\mathrm{n}=11)\end{array}$ & $\begin{array}{c}\text { Indu } \\
(\mathrm{n}=8)\end{array}$ & $\begin{array}{c}\text { IAC } \\
(\mathrm{n}=18) \\
\end{array}$ & $\begin{array}{l}\text { Mons } \\
(\mathrm{n}=38)\end{array}$ & $\begin{array}{c}\text { Total } \\
(n=154)\end{array}$ \\
\hline \multirow[t]{8}{*}{ Satt 173* } & 205 & - & - & - & - & 0,056 & 0,026 & 0,013 \\
\hline & 217 & 0,157 & $(0,389)$ & $(0,364)$ & - & 0,111 & 0,066 & 0,149 \\
\hline & 220 & 0,100 & 0,111 & 0,182 & - & $(0,556)$ & 0,158 & 0,169 \\
\hline & 232 & 0,029 & - & - & 0,125 & - & - & 0,019 \\
\hline & 244 & 0,086 & 0,111 & - & - & - & 0,026 & 0,052 \\
\hline & 250 & 0,043 & 0,056 & - & - & 0,111 & 0,066 & 0,052 \\
\hline & 266 & $(0,414)$ & 0,278 & 0,273 & $(0,875)$ & 0,167 & $(0,632)$ & $(0,445)$ \\
\hline & 281 & 0,171 & 0,056 & 0,182 & - & - & 0,026 & 0,101 \\
\hline \multirow[t]{7}{*}{ Satt009* } & 178 & 0,186 & 0,111 & $(0,409)$ & $(0,625)$ & 0,278 & 0,105 & 0,211 \\
\hline & 205 & 0,221 & 0,278 & 0,091 & 0,125 & 0,167 & 0,250 & 0,211 \\
\hline & 226 & 0,114 & - & 0,091 & - & - & 0,026 & 0,065 \\
\hline & 229 & 0,064 & 0,222 & 0,091 & - & - & 0,145 & 0,084 \\
\hline & 241 & $(0,329)$ & $(0,389)$ & 0,227 & 0,250 & $(0,500)$ & $(0,303)$ & $(0,334)$ \\
\hline & 247 & 0,043 & - & - & - & 0,056 & 0,026 & 0,032 \\
\hline & 262 & 0,043 & - & 0,091 & - & - & 0,145 & 0,062 \\
\hline \multirow[t]{4}{*}{ Satt002* } & 121 & - & - & 0,091 & - & - & - & 0,006 \\
\hline & 133 & 0,379 & $(0,556)$ & $(0,455)$ & $(0,500)$ & $(0,500)$ & $(0,526)$ & 0,451 \\
\hline & 142 & $(0,536)$ & 0,222 & $(0,455)$ & 0,375 & 0,389 & 0,421 & $(0,458)$ \\
\hline & 148 & 0,086 & 0,222 & - & 0,125 & 0,111 & 0,053 & 0,084 \\
\hline \multirow[t]{7}{*}{ Satt005* } & 153 & - & - & - & - & 0,056 & - & 0,006 \\
\hline & 162 & 0,143 & - & - & - & 0,222 & - & 0,091 \\
\hline & 168 & - & - & 0,091 & - & - & 0,053 & 0,019 \\
\hline & 171 & 0,171 & 0,333 & 0,273 & - & 0,222 & 0,303 & 0,218 \\
\hline & 174 & $(0,614)$ & $(0,667)$ & $(0,636)$ & $(0,875)$ & $(0,333)$ & $(0,526)$ & $(0,578)$ \\
\hline & 195 & 0,043 & - & - & 0,125 & 0,167 & 0,118 & 0,075 \\
\hline & 198 & 0,029 & - & - & - & - & - & 0,013 \\
\hline
\end{tabular}

(1)Embr: Embrapa; AgGo: Agência Goiana e Emater (GO); Cood: Coodetec; Indu: Indusem e Rudiger Boye; IAC: Instituto Agronômico; Mons: Monsoy. ${ }^{(2)}$ Tamanho amostral. ${ }^{(3)}$ Alelo não encontrado. *Significativo a $5 \%$ de probabilidade (nível de significância para $\mathrm{H}_{0}$ (distribuição alélica idêntica entre as populações)).

relatada em estudo de diversidade genética de soja visando a introgressão de genes de PIs (Plant Introductions) em cultivares-elite de programas americanos de melhoramento (Narvel et al., 2000), inclusive com os locos Satt002, Satt005, Satt009, Satt173, Satt307 também aqui utilizados. Segundo estes autores, do total de 397 alelos de 74 locos SSRs utilizados, 138 foram exclusivos dos PIs e 32 das cultivares-elite. Abe et al. (2003), comparando acessos e linhagens de soja provenientes da China e do Japão, encontraram 44 alelos exclusivos da população japonesa e 71 exclusivos da população chinesa do total de 212 alelos estudados em 20 locos SSR.

Em quatro dos 12 locos avaliados, os alelos mais freqüentes nos diferentes programas (alelos 159 - Satt102, 156 - Satt335, 181- Satt307 e 174 - Satt005) foram sempre os mesmos, o que pode ser indicativo da maior importância de caracteres ligados a estes para o melhoramento da cultura. A presença de alelos mais freqüentes em detrimento de outros não chegou a ser surpreendente, uma vez que a amostra é constituída de cultivareselite, que sofreram, portanto, maior pressão de seleção.
Mesmo considerando que estes locos SSR não tenham funções ou associações definidas, esta pressão pode ter sido resultante da sua maior relevância para os programas de melhoramento. Kashi \& Soller (1998), por exemplo, sugeriram que alguns microssatélites estejam associados à codificação de proteínas e também ao processo de transcrição em muitos organismos. Vários locos microssatélites em soja apresentaram associação com resistência a doenças em estudos de mapeamento, como os locos Satt244 e Satt547, que estão ligados à resistência ao fungo Cercospora sojina Hara (Mian et al., 1999), os locos Satt082, Sat_001, Satt574 e Satt301, associados à resistência ao nematóide-de-cisto Heterodera glycines (Schuster et al., 2001) e o loco Satt309 (utilizado neste estudo) que está associado à resistência ao Fusarium solani f. sp. glycines (Fronza, 2003). Um outro microssatélite utilizado, o Satt002, está localizado a $10 \mathrm{cM}$ do gene da malato desidrogenase (Palmer et al., 1992).

A análise de variância molecular mostrou diferenças significativas entre programas de melhoramento $(5,3 \%$, $\mathrm{p}<0,05)$ e entre cultivares dentro de programas de me- 
lhoramento $(94,7 \%, \mathrm{p}<0,05)$. A maior porção de variação entre cultivares dentro de programas foi, provavelmente, decorrente do elevado nível de polimorfismo dos marcadores utilizados.

O polimorfismo deste conjunto de locos microssatélites já havia sido observado na determinação de perfis neste grupo de cultivares (Priolli et al., 2002). Entretanto, Alcantara Neto (2001) não observou polimorfismo em três dos 12 locos aqui estudados (Satt002, Satt005 e Satt009) em um grupo de 32 cultivares brasileiras. Tais resultados podem ser decorrentes das condições mais rigorosas de sua PCR em relação às deste estudo (temperatura de pareamento de $50^{\circ} \mathrm{C}$, superior a $47^{\circ} \mathrm{C}$ ).

Quando comparados os programas de melhoramento pelo teste $F_{S T}$ (Tabela 3), apenas cinco (Embrapa/IAC, Embrapa/Monsoy, AgGo/IAC, Indusem/IAC, IAC/ Monsoy) dos 15 pares de comparações tiveram diferenças significativas entre $\mathrm{si}(\mathrm{p}<0,05)$, estando presente o programa IAC em quatro destas comparações.

Tabela 3. Comparações entre programas de melhoramento por meio dos valores de variância das frequiências gênicas $\left(F_{S T}\right)^{(1)}$.

\begin{tabular}{lccccc}
\hline & Embr & AgGo & Cood & Indu & IAC \\
\hline AgGo & $0,0049^{\text {ns }}$ & & & & \\
Cood & $0,0033^{\text {ns }}$ & $0,0001^{\text {ns }}$ & & & \\
Indu & $0,0444^{\text {ns }}$ & $0,0492^{\text {ns }}$ & $0,0584^{\text {ns }}$ & & \\
IAC & $0,0610^{* *}$ & $0,0402^{*}$ & $0,0300^{\text {ns }}$ & $0,0806^{*}$ & \\
Mons & $0,0170^{*}$ & $0,0144^{\text {ns }}$ & $0,0236^{\text {ns }}$ & $0,0278^{\text {ns }}$ & $0,0590^{* *}$ \\
\hline
\end{tabular}

${ }^{(1)}$ Embr: Embrapa; AgGo: Agência Goiana e Emater (GO); Cood: Coodetec; Indu: Indusem e Rudiger Boye; IAC: Instituto Agronômico; Mons: Monsoy. ${ }^{\text {ns }}$ Não significativo. ${ }^{*} \mathrm{e} * *$ Significativo a $5 \%$ e a $1 \%$ de probabilidade, respectivamente, pelo procedimento de bootstrap com 1.000 replicações.
A distinção deste grupo de cultivares, somada aos resultados de maior valor de diversidade genética por este programa de melhoramento, não parece decorrer do menor número de indivíduos analisados (18 cultivares) em relação aos programas Embrapa (70 cultivares) ou Monsoy (28 cultivares), pois Coodetec, Ag. Goiana e Indusem tiveram, respectivamente, 11, 9 e 8 cultivares analisadas, número inferior ao do grupo IAC. Entretanto, uma análise mais detalhada da genealogia deste grupo de cultivares (Priolli et al., 2002) revelou que 12 entre as 18 cultivares descendem das cultivares Paraná e IAC 8, sendo que estas descendem da cultivar Hill. Deste modo, com a maior endogamia, não chegou a ser surpreendente que existisse maior heterogeneidade (ou estruturação) neste programa, em relação aos demais. O maior índice de diversidade apresentado por este programa também pode estar relacionado a esta composição, uma vez que a mistura do conjunto de 12 cultivares (provavelmente pouco divergentes) com seis cultivares (provavelmente mais divergentes) pode ter elevado este valor. Uma outra explicação para esta maior diversidade pode estar relacionada com sua própria idade, uma vez que o acúmulo de mutações neste programa seria maior e, conseqüentemente, a diversidade. De acordo com Miranda et al. (1982), o programa de melhoramento de soja do IAC é um dos mais antigos do país, e tem contribuído desde a década de 50 para o desenvolvimento de cultivares resistentes a diversos patógenos e pragas além de adaptadas a baixas latitudes.

\section{Variabilidade genética entre períodos}

A diversidade alélica nos cinco períodos apontou polimorfismo em todos os locos estudados (Tabela 4). A média de diversidade genética de maior valor

Tabela 4. Número de alelos e índices de diversidade genética (DG) por loco em períodos de lançamento de cultivares de soja ${ }^{(1)}$.

\begin{tabular}{|c|c|c|c|c|c|c|c|c|c|c|c|c|c|}
\hline \multirow[t]{2}{*}{ Loco } & \multicolumn{6}{|c|}{ Número de alelos } & \multicolumn{7}{|c|}{ Diversidade genética por loco e população } \\
\hline & $\begin{array}{l}<1979 \\
(\mathrm{n}=11)^{(2)}\end{array}$ & $\begin{array}{r}80 / 84 \\
(\mathrm{n}=28) \\
\end{array}$ & $\begin{array}{c}85 / 89 \\
(\mathrm{n}=35) \\
\end{array}$ & $\begin{array}{c}90 / 94 \\
(\mathrm{n}=27)\end{array}$ & $\begin{array}{r}95 / 99 \\
(\mathrm{n}=83)\end{array}$ & $\begin{array}{c}\text { Todos } \\
(\mathrm{n}=184)\end{array}$ & & $\begin{array}{l}<1979 \\
(n=11)\end{array}$ & $\begin{array}{r}80 / 84 \\
(\mathrm{n}=28) \\
\end{array}$ & $\begin{array}{c}85 / 89 \\
(\mathrm{n}=35)\end{array}$ & $\begin{array}{c}90 / 94 \\
(\mathrm{n}=27)\end{array}$ & $\begin{array}{r}95 / 99 \\
(\mathrm{n}=83) \\
\end{array}$ & $\begin{array}{r}\text { Todos } \\
(\mathrm{n}=184)\end{array}$ \\
\hline Satt308 & 6 & 7 & 7 & 7 & 7 & 7 & & 0,855 & 0,828 & 0,849 & 0,826 & 0,828 & 0,837 \\
\hline Sct_189 & 4 & 5 & 5 & 5 & 5 & 5 & & 0,745 & 0,767 & 0,803 & 0,803 & 0,794 & 0,782 \\
\hline Satt406 & 4 & 6 & 7 & 6 & 7 & 7 & & 0,836 & 0,712 & 0,631 & 0,836 & 0,775 & 0,757 \\
\hline Satt309 & 4 & 5 & 5 & 5 & 5 & 5 & & 0,709 & 0,746 & 0,739 & 0,715 & 0,703 & 0,723 \\
\hline Satt 102 & 5 & 6 & 6 & 8 & 7 & 8 & & 0,600 & 0,726 & 0,743 & 0,798 & 0,718 & 0,718 \\
\hline Satt335 & 4 & 4 & 4 & 3 & 4 & 4 & & 0,673 & 0,660 & 0,713 & 0,611 & 0,616 & 0,654 \\
\hline Satt263 & 3 & 3 & 3 & 4 & 3 & 4 & & 0,564 & 0,702 & 0,667 & 0,681 & 0,526 & 0,628 \\
\hline Satt307 & 3 & 4 & 4 & 3 & 4 & 4 & & 0,618 & 0,519 & 0,590 & 0,644 & 0,580 & 0,590 \\
\hline Satt 173 & 3 & 5 & 6 & 6 & 5 & 8 & & 0,259 & 0,637 & 0,630 & 0,492 & 0,588 & 0,526 \\
\hline Satt009 & 2 & 4 & 4 & 3 & 3 & 4 & & 0,509 & 0,423 & 0,580 & 0,530 & 0,571 & 0,523 \\
\hline Satt002 & 2 & 3 & 4 & 3 & 4 & 4 & & 0,473 & 0,439 & 0,572 & 0,385 & 0,318 & 0,437 \\
\hline Satt005 & 3 & 3 & 4 & 4 & 4 & 4 & & 0,182 & 0,402 & 0,469 & 0,553 & 0,552 & 0,435 \\
\hline Média & 3,58 & 4,58 & 4,92 & 4,75 & 4,83 & 5,33 & DG & 0,585 & 0,630 & 0,665 & 0,656 & 0,630 & 0,634 \\
\hline Total & 43 & 55 & 59 & 57 & 58 & 64 & $\pm \mathrm{SD}$ & 0,06 & 0,04 & 0,03 & 0,04 & 0,04 & 0,04 \\
\hline
\end{tabular}

(1)<1979: cultivares lançadas até 1979; 80/84: cultivares lançadas entre 1980 e 1984; 85/89: cultivares lançadas entre 1985 e 1989; 90/94: cultivares lançadas entre 1990 e 1994; 95/99: cultivares lançadas entre 1995 e 1999; SD: erro padrão. ${ }^{(2)}$ Tamanho amostral. 
$(\mathrm{DG}=0,665)$ foi observada no período que apresentou maior número de alelos, enquanto a média de diversidade genética de menor valor $(\mathrm{DG}=0,585)$ foi observada no período de menor número de alelos. Entretanto, como citado anteriormente na análise entre programas, aparentemente não há relação entre estes índices.

Considerando as frequiências dos alelos dos 12 locos, três foram exclusivos de alguns períodos, alelos 121 - Satt002, 153 - Satt005 e 198 - Satt005, tendo somente este último apresentado freqüência superior a 0,01 (Tabela 5). Do total de 64 alelos detectados, 25 $(39,1 \%)$ não estiveram presentes em alguns períodos.

A distribuição da freqüência dos alelos entre períodos variou pelo teste exato em oito locos avaliados. So-

Tabela 5. Frequiências gênicas de 12 locos SSR em cultivares de soja de cinco períodos e valores de probabilidade obtidos para diferenciação gênica. Os alelos mais comuns de cada loco em cada período estão entre parênteses ${ }^{(1)}$.

\begin{tabular}{|c|c|c|c|c|c|c|c|}
\hline \multirow[t]{2}{*}{ Loco } & \multirow{2}{*}{$\begin{array}{l}\text { Alelo } \\
(\mathrm{pb})\end{array}$} & \multicolumn{5}{|c|}{ Freqüências gênicas } & \multirow[b]{2}{*}{$\begin{array}{c}\text { Todos } \\
(\mathrm{n}=184)\end{array}$} \\
\hline & & $\begin{array}{l}<1979 \\
(\mathrm{n}=11)^{(2)}\end{array}$ & $\begin{array}{c}80 / 84 \\
(n=28)\end{array}$ & $\begin{array}{c}85 / 89 \\
(\mathrm{n}=35)\end{array}$ & $\begin{array}{l}90 / 94 \\
(\mathrm{n}=27)\end{array}$ & $\begin{array}{c}95 / 99 \\
(\mathrm{n}=83)\end{array}$ & \\
\hline \multirow[t]{7}{*}{ Satt308* } & 147 & 0,091 & 0,071 & 0,057 & 0,111 & 0,096 & 0,087 \\
\hline & 162 & & $(0,286)$ & 0,157 & & 0,217 & 0,193 \\
\hline & 168 & $(0,364)$ & 0,214 & $(0,257)$ & 0,185 & $(0,265)$ & $(0,250)$ \\
\hline & 171 & & 0,036 & & & & 0,046 \\
\hline & 17 & 0,091 & 0,036 & & & & \\
\hline & 18 & & & & & & \\
\hline & & & & & & & \\
\hline \multirow{5}{*}{ Sct_189* } & 178 & $(0,636)$ & $(0,429)$ & $(0,400)$ & & $(0$, & $(0,408)$ \\
\hline & 181 & - & & & & & \\
\hline & 20 & & & & & & \\
\hline & & & & & & & \\
\hline & & & & & & 0,1 & \\
\hline \multirow[t]{4}{*}{ Satt406* } & 25 & $(0,5$ & $(0,482)$ & $(0,400)$ & $(0$, & $(0,506)$ & $(0,489)$ \\
\hline & & & & & 0,1 & 0,145 & 0,147 \\
\hline & & & & & & & \\
\hline & & & 0,321 & & 0,3 & & 0,326 \\
\hline \multirow[t]{4}{*}{ Satt309* } & 13 & 0,36 & 0,232 & $(0,543)$ & 0,296 & 0,386 & 0,378 \\
\hline & 14 & $(0,636$ & $(0,732)$ & 0,371 & $(0,630)$ & $(0,530)$ & $(0,552)$ \\
\hline & 14 & - & 0,036 & 0,057 & 0,074 & 0,072 & 0,060 \\
\hline & & - & & 0,0 & & 0,012 & 0,011 \\
\hline \multirow[t]{4}{*}{ Satt $102 *$} & 14 & 0,182 & 0,179 & & & & \\
\hline & 15 & & 0,089 & & 0,074 & 0,108 & 0,098 \\
\hline & 15 & $(0,727)$ & $(0,732)$ & $(0,629)$ & $(0,778)$ & $(0,819)$ & $(0,758)$ \\
\hline & 16 & 0,091 & - & 0,086 & 0,019 & 0,030 & 0,038 \\
\hline \multirow[t]{4}{*}{ Satt335* } & 150 & - & 0,054 & 0,029 & - & 0,012 & 0,019 \\
\hline & 156 & $(0,864)$ & $(0,536)$ & $(0,543)$ & $(0,667)$ & $(0,578)$ & $(0,595)$ \\
\hline & 162 & & 0,143 & 0,214 & 0,278 & 0,217 & 0,204 \\
\hline & 16 & & & & & 0,193 & 0,182 \\
\hline \multirow[t]{5}{*}{ Satt263* } & 214 & 0,091 & 0,054 & & 0,037 & 0,054 & 0,063 \\
\hline & 223 & - & & & 0,111 & 0,193 & 0,160 \\
\hline & 235 & & & & & & \\
\hline & 238 & $(0,455)$ & 0,304 & 0,314 & $(0,444)$ & 0,301 & 0,334 \\
\hline & 247 & 0,364 & $(0,375)$ & $(0,386)$ & 0,296 & $(0,416)$ & $(0,383)$ \\
\hline \multirow[t]{4}{*}{ Satt307* } & 166 & - & & & - & - & 0,011 \\
\hline & 175 & 0,091 & 0,125 & 0,143 & 0,074 & 0,108 & 0,111 \\
\hline & 181 & $(0,909)$ & $(0,768)$ & $(0,714)$ & $(0,593)$ & $(0,596)$ & $(0,663)$ \\
\hline & & - & 0,071 & 0,114 & 0,333 & 0,295 & 0,215 \\
\hline
\end{tabular}
Continua...
Tabela 5. Continuação.

\begin{tabular}{|c|c|c|c|c|c|c|c|}
\hline \multirow[t]{2}{*}{ Loco } & \multirow{2}{*}{$\begin{array}{l}\text { Alelo } \\
(\mathrm{pb})\end{array}$} & \multicolumn{6}{|c|}{ Frequiências gênicas } \\
\hline & & $\begin{array}{l}<1979 \\
(\mathrm{n}=11)^{(}\end{array}$ & $\begin{array}{r}80 / 84 \\
\text { (2) }(\mathrm{n}=28)\end{array}$ & $\begin{array}{r}85 / 89 \\
(\mathrm{n}=35)\end{array}$ & $\begin{array}{c}90 / 94 \\
(n=27)\end{array}$ & $\begin{array}{r}95 / 99 \\
(n=83)\end{array}$ & $\begin{array}{c}\text { Todos } \\
(n=184)\end{array}$ \\
\hline \multirow[t]{8}{*}{ Satt $173 *$} & 205 & - & - & 0,029 & 0,037 & - & 0,011 \\
\hline & 217 & 0,182 & 0,143 & 0,043 & 0,204 & 0,181 & 0,152 \\
\hline & 220 & 0,182 & 0,143 & 0,257 & 0,222 & 0,133 & 0,174 \\
\hline & 232 & - & - & - & 0,037 & 0,024 & 0,016 \\
\hline & 244 & 0,091 & 0,036 & - & 0,074 & 0,072 & 0,054 \\
\hline & 250 & - & 0,036 & 0,043 & 0,019 & 0,072 & 0,049 \\
\hline & 266 & $(0,364)$ & $(0,500)$ & $(0,557)$ & $(0,278)$ & $(0,398)$ & $(0,424)$ \\
\hline & 281 & 0,182 & 0,143 & 0,071 & 0,130 & 0,120 & 0,120 \\
\hline \multirow[t]{7}{*}{ Satt009* } & 178 & 0,273 & 0,214 & 0,186 & $(0,315)$ & 0,2 & 0,226 \\
\hline & 205 & 0,182 & 0,250 & 0,257 & 0,148 & 0,2 & 0,220 \\
\hline & 226 & - & - & 0,029 & 0,111 & 0,0 & 0,054 \\
\hline & 229 & - & 0,018 & 0,043 & 0,111 & 0, & 0,073 \\
\hline & 241 & $(0,455)$ & $(0,375)$ & $(0,300)$ & 0,278 & $(0,319)$ & $(0,326)$ \\
\hline & 247 & - & 0,071 & 0,029 & - & 0,048 & 0,038 \\
\hline & 262 & 0,091 & 0,071 & 0,157 & 0,037 & 0,024 & 0,0 \\
\hline \multirow[t]{4}{*}{ Satt002 ${ }^{\text {ns }}$} & 121 & - & - & - & 0,037 & - & 0,005 \\
\hline & 133 & $(0,545)$ & $(0,643)$ & $(0,486)$ & 0,389 & 0,440 & $(0,478)$ \\
\hline & 142 & 0,364 & 0,286 & 0,429 & $(0,463)$ & $(0,476)$ & 0,429 \\
\hline & 148 & 0,091 & 0,071 & 0,086 & 0,111 & 0,084 & 0,087 \\
\hline \multirow[t]{8}{*}{ Satt005* } & 153 & - & - & - & 0,037 & - & 0,005 \\
\hline & 162 & 0,273 & 0,143 & 0,029 & 0,037 & 0,120 & 0,103 \\
\hline & 168 & - & 0,071 & 0,057 & 0,037 & - & 0,027 \\
\hline & 171 & - & 0,196 & 0,400 & 0,222 & 0,157 & 0,209 \\
\hline & 174 & $(0,636)$ & $(0,500)$ & $(0,429)$ & $(0,519)$ & $(0,663)$ & $(0,571)$ \\
\hline & 177 & 0,091 & - & 0,029 & - & - & 0,011 \\
\hline & 195 & - & 0,089 & 0,057 & 0,148 & 0,036 & 0,063 \\
\hline & 198 & - & - & - & - & 0,024 & 0,011 \\
\hline
\end{tabular}

(1)<1979: cultivares lançadas até 1979; 80/84: cultivares lançadas entre 1980 e 1984; 85/89: cultivares lançadas entre 1985 e 1989; 90/94: cultivares lançadas entre 1990 e 1994; 95/99: cultivares lançadas entre 1995 e 1999. ${ }^{(2)}$ Tamanho amostral. ${ }^{(3)}$ Alelo não encontrado. ${ }^{\text {ns Não- }}$ significativo. *Significativo a 5\% de probabilidade (nível de significância para $\mathrm{H}_{0}$ (distribuição alélica idêntica entre as populações)).

mente os locos Satt308, Satt406, Satt263 e Satt002 não apresentaram distribuição significativamente diferente dos seus alelos nos períodos, fato que pode sugerir menor pressão de seleção sobre eles. A freqüência de alelos SSR também apresentou distribuição uniforme na maioria dos 18 locos SSR estudados em 67 linhagens e cultivares de soja provenientes do Banco de Germoplasma da Eslováquia (Hudcovicová \& Kraic, 2003). Os alelos 257 - Satt406, 159 - Satt102, 156 - Satt335, 181 - Satt307, 266 - Satt173 e 174 - Satt005, mantiveram-se destacados em todos os períodos, sugerindo que houve fixação ao longo do tempo. Com exceção dos alelos 257 - Satt406 e 266 - Satt173, os quatro alelos dos respectivos locos apresentaram este mesmo comportamento nas comparações entre programas de melhoramento.

A AMOVA não mostrou diferenças significativas entre períodos $(1,78 \%, \mathrm{p}>0,05)$, sendo que a maior porção de variância encontrada foi devida a diferenças entre cultivares dentro de períodos de lançamento $(98,22 \%$, 
$\mathrm{p}>0,05)$. Tampouco as análises entre os pares de períodos pelo teste $F_{S T}$ revelaram diferenças entre eles. Tais resultados sugerem a homogeneidade entre períodos, ou seja, a manutenção da diversidade genética do germoplasma cultivado ao longo do tempo.

Isto não era esperado, uma vez que os programas de melhoramento de soja tiveram diferentes objetivos ao longo do tempo, o que deveria ter elevado a heterogeneidade entre períodos. De acordo com Sediyama et al. (1999), na década de 70, o principal alvo dos programas de melhoramento de soja foi o desenvolvimento de plantas altas, mais tardias e resistentes à pústula bacteriana (Xanthomonas phaseoli pv. glycines). Na década de 80, o objetivo principal foi a expansão das cultivares com PJL e também resistentes à mancha-olho-de-rã, causada por Cercospora sojina Hara. Na década de 90, os programas se preocupavam em desenvolver cultivares resistentes ao cancro-da-haste, causado por Diaphorte phaseolorum f. sp. meridionalis, ao nematóide-do-cisto, causado por Heterodera glycines Ichinohe e ao oídio, causado por Microsphaera diffusa. Como o lançamento de novas cultivares pelas instituições públicas e privadas principalmente nas décadas de 70, 80 e 90, com a ampliação do cultivo para áreas do cerrado brasileiro, esta expansão pode ter possibilitado um equilíbrio entre os fatores que levariam à erosão genética. Uma análise mais detalhada da genealogia deste grupo de cultivares revelou que alelos de antigas cultivares (Santa Rosa, IAC 8, FT Cristalina, Paraná) foram preservados nas cultivares mais recentes, mas a variabilidade do grupo foi mantida pela introdução de outros materiais (Centennial, Stonewall, Forrest, alguns PIs) mais resistentes a patógenos prejudiciais à cultura.

Outro indício desta relação de equilíbrio entre materiais introduzidos e mantidos sobre a diversidade genética pode ser observado na coincidência de que o período 1985/1989 é o de maior número de alelos e maior índice de diversidade, como também de lançamento das primeiras cultivares resistentes ao cancro-da-haste. Embora esta diferença não tenha sido significativa na AMOVA e $F_{S T}$, a pequena superioridade destes valores parece refletir o esforço dos programas de melhoramento na busca de novas fontes de resistência ao cancro, que estava colocando em risco o cultivo da soja.

Resultados similares sobre a manutenção de diversidade genética ao longo do tempo foram recentemente relatados em cultivares de trigo na Grã-Bretanha por Donini et al. (2000) e na Argentina por Manifesto et al. (2001). As análises dos marcadores SSR indicaram que o melhoramento de trigo nesses países tem resultado mais em uma mudança qualitativa do que quantitativa, com o tempo.

\section{Conclusões}

1. Os programas de melhoramento de soja no Brasil apresentam maior variabilidade intra do que intergrupos.

2. Há maior heterogeneidade no programa de melhoramento de soja do IAC em relação aos programas Embrapa, Agência Goiana/Emater, GO, Indusem/RB e Monsoy.

3. Os períodos de lançamento das cultivares de soja apresentam maior porção de variabilidade intra do que intergrupos.

4. O germoplasma brasileiro de soja mantém variabilidade genética constante nos últimos 30 anos de expansão e melhoramento da cultura.

\section{Agradecimentos}

À Capes e FAEPA-HC-FMRP, pelo financiamento da pesquisa; aos pesquisadores Leones de Almeida, Milton Kaster, Roberto Zito e Nelson R. Braga, pelo fornecimento das sementes das cultivares utilizadas.

\section{Referências}

ABE, J.; XU, D.H.; SUSUKI, Y.; KANASAWA, A.; SHIMAMOTO, Y. Soybean germplasm pools in Asia revealed by nuclear SSRs. Theoretical and Applied Genetics, v.106, p.445453, 2003.

ALCANTARA NETO, F. Marcadores microssatélites na identificação de cultivares de soja. 2001. 57p. Dissertação (Mestrado) - Universidade Federal de Viçosa, Viçosa.

BONETTI, L.P. Cultivares e seu melhoramento genético. In: VERNETTI, F.J. Soja - genética e melhoramento. Campinas: Fundação Cargill, 1983. p.741-800.

CLUNIES-ROSS, T. Mangolds, manure and mixtures: the importance of crop diversity on British farms. Ecologist, v.25, p.181-187, 1995.

CREGAN, P.B.; JARVIK, T.; BUSH, A.L.; SHOEMAKER, R.C.; LARK, K.G.; KAHLER, A.L.; KAYA, N.; VANTOAI, T.T.; LOHNES, D.G.; CHUNG, J.; SPECHT, J.E. An integrated genetic linkage map of the soybean genome. Crop Science, v.39, p.14641490, 1999.

DONINI, P.; LAW, J.R.; KOEBNER, R.M.D.; REEVES, J.C.; COOKE, R.J. Temporal trends in the diversity of UK wheat. Theoretical and Applied Genetics, v.100, p.912-917, 2000. 
DOYLE, J.J.; DOYLE, J.L. Isolation of plant DNA from fresh tissue. Focus, v.12, p.13-15, 1990.

ESTADOS UNIDOS. Department of Agriculture. Agricultural Research Service. Soybean genome database. Disponível em: <http:/ /129.186.26.94/SSR.html> Acesso em: 20 fev. 2003.

FRONZA, V. Genética da reação da soja a Fusarium solani f. sp. glycines. 2003. 154p. Tese (Doutorado) - Escola Superior de Agricultura Luiz de Queiroz, Piracicaba.

GIZLICE, Z.; CARTER JUNIOR, T.E.; BURTON, J.W. Genetic diversity in North American soybean: Multivariate analysis of founding stock and relation to coefficient of parentage. Crop Science, v.33, p.614-617, 1993.

GOUDET, J. FSTAT (version 1.2): a computer program to calculate F-statistics. Journal of Heredity, v.86, p.485-486, 1995.

HARTL, D.; CLARK, A. Principles of population genetics. Sunderland: Sinauer Associates Inc. 1997. 542p.

HIROMOTO, D.M.; VELLO, N.A. The genetic base of Brazilian soybean Glycine $\max$ (L.) Merril) cultivars. Revista Brasileira de Genética, v.9, p.295-306, 1986.

HUDCOVICOVÁ, M.; KRAIC, J. Utilisation of SSRs for characterisation of the soybean (Glycine $\max$ (L.) Merr.) genetic resources. Czech Journal of Genetics and Plant Breeding, v.39, p.120-126, 2003.

KASHI, Y.; SOLLER, M. Functional roles of microsatellites and minisatellites. In: GOLDSTEIN, D.B.; SCHLÖTTERER, C. (Ed.). Microsatellites: evolution and applications. Oxford: Oxford University Press, 1998, p.10-22.

LEWIS, P.O.; ZAYKIN, D. Genetic data analysis: software for the analysis of discrete genetic data. Version 1.0. Sunderland: Sinauer Associates Inc., 1997.

MCGRATH, J.M.; DERRICO, C.A.; YU, Y. Genetic diversity in selected, historical US sugarbeet germplasm and Beta vulgaris ssp. maritima. Theoretical and Applied Genetics, v.98, p.968-976, 1999.

MANIFESTO, M.M.; SCHLATTER, A.R.; HOPP, H.E.; SUÁREZ, E.Y.; DUBCOVSKY, J. Quantitative evaluation of genetic diversity in wheat germplasm using molecular markers. Crop Science, Madison, v.41, p.682-690, 2001.

MIAN, M.A.R.; WANG, T.; PHILLIPS, D.V.; ALVERNAZ, J.; BOERMA, H.R. Molecular mapping of the Rcs 3 gene for resistance to frogeye leaf spot in soybean. Crop Science, v.39, p.1687-1691, 1999.

MIRANDA, M.A.C. de; MIYASAKA, S.; MASCARENHAS, H.A.A. Melhoramento da soja no Estado de São Paulo. In:
FUNDAÇÃO CARGILL. A soja no Brasil Central. Campinas: Fundação Cargill, 1982. p.181-188.

NARVEL, J.M.; FEHR, W.R.; CHU, W.C.; GRANT, D.; SHOEMAKER, R.C. Simple sequence repeat diversity among soybean plant introductions and elite genotypes. Crop Science, v.40, p.1452-1458, 2000.

PALMER, R.G.; LIM SUNG, M.; HEDGES, B.R. Testing for linkage between the Rxp locus and nine isozyme loci in soybean. Crop Science, v.32, p.681-683, 1992.

PALUDZYSZYN FILHO, E.; KIIHL, R.A. de S.; ALMEIDA, L.A. Desenvolvimento de cultivares de soja na região Norte e Nordeste do Brasil. In: ARANTES, N.E.; SOUZA, P.I. de M. de (Ed.). Cultura da soja nos cerrados. Piracicaba: Potafos, 1993. p.255-266.

PRIOLLI, R.H.G.; MENDES-JUNIOR, C.T.; ARANTES, N.E.; CONTEL, E.P.B. Characterization of Brazilian soybean cultivars using microsatellite markers. Genetics and Molecular Biology, v.25, p.185-193, 2002.

RAYMOND, M.; ROUSSET, F. An exact test for population differentiation. Evolution, v.49, p.1280-1283, 1995a.

RAYMOND, M.; ROUSSET, F. GENEPOP (version 1.2): population genetics software for exact tests and ecumenism. Journal of Heredity, v.86, p.248-249, 1995 b.

SANGUINETTI, C.; DIAS-NETO, E.; SIMPSON, A.J.G. RAPD silver staining and recovery of PCR products separated on polyacrylamide gels. Biotechniques, v.17, p.914-921, 1994.

SCHNEIDER, S.; ROESSLI, D.; EXCOFFIER, L. Arlequin version 2000: a software for population genetics data analysis. Geneva: Genetics and Biometry Laboratory, University of Geneva, 2000.

SCHUSTER, I.; ABDELNOOR, R.V.; MARIN, S.R.R.; CARVALHO, V.P.; KIIHL, R.A.S.; SILVA, J.F.V.; SEDIYAMA, C.S.; BARROS, E.G.; MOREIRA, M.A. Identification of a new major QTL associated with resistance to soybean cyst nematode (Heterodera glycines). Theoretical and Applied Genetics, v.102, p.91-96, 2001.

SEDIYAMA, T.; TEIXEIRA, R. de C.; REIS, M.S. Melhoramento da soja. In: BORÉM, A. (Ed.). Melhoramento de espécies cultivadas. Viçosa: UFV, 1999. p.487-533.

URBEN FILHO, G.; SOUZA, P. I. de M. de. Manejo da cultura da soja sob cerrado: época, densidade e profundidade de semeadura. In: ARANTES, N.E.; SOUZA, P.I. de M. de (Ed.). Cultura da soja nos cerrados. Piracicaba: Potafos, 1993. p.267-298.

VELLVÉ, R. The decline of diversity in European agriculture. Ecologist, v.23, p.64-69, 1993.

Recebido em 27 de novembro de 2003 e aprovado em 9 de junho de 2004 